Revista Iberoamericana, Vol. LXXVIII, Núm. 241, Octubre-Diciembre 2012, 1069-1075

\title{
DIÁLOGO CON DANIEL LINK
}

\author{
POR \\ NANCY FERNÁNDEZ \\ CONICET-UNMDP
}

La siguiente entrevista a Daniel Link fue realizada por Nancy Fernández el 18 de septiembre de 2009, en el marco de su visita a la Facultad de Humanidades de la Universidad Nacional de Mar del Plata por invitación del grupo de investigación Literatura, política y cambio. Edgardo H. Berg presentó al invitado y Joaquín Correa expuso su lectura crítica sobre Fantasmas. Imaginación y sociedad.

NANCY FERnÁNDEZ: Un primer problema que formula Fantasmas es el de lo real y la referencia. En principio, a partir de la noción de lo imaginario (y la imaginación), del deseo, figurados en la potencia seductora que sintetiza y apela a la forma de una cesura: las sirenas. El silencio de un canto implacable que sobrevive (y sobreviene) a la cultura y sus dispositivos que organizan (administran) las prácticas artísticas y retóricas del sujeto y la comunidad. En parte esos mecanismos tendrían que ver con las divisiones (estructurales, abstractas) entre autonomía (lo específico de la literatura) y “exteriordidad”, noción que vos reconstruís en el capítulo sobre intimidad y discutís concretamente en la parte sobre Martín Kohan. ¿Podemos pensar el lugar de lo real y del realismo (con su fundamento en lo imaginario) desde la idea de posautonomía (Ludmer) o desde términos que permitan replantear nuestra relación con los saberes, con las prácticas, con lo social, más allá de divisiones entre adentro/afuera? A partir de varios filósofos que trabajás (Sloterdijk, Agamben, también Esposito y sobre todo Negri) creo que se puede pensar en una categoría como la de bioficción. Desde esta perspectiva, ¿̇e podrían situar algunas producciones contemporáneas?

DANiEl Link: Empiezo por el final. Sí, me parece que a partir de esas referencias bibliográficas (Sloterdijk, Agamben, Esposito, Negri) se podría hablar de algo así como "bioestética”, que agrupa más problemas que la noción de “bioficción”. Es una problemática que, en efecto, me interesa desde hace mucho (pienso, sobre todo, en mi trabajo en relación con la ciencia ficción: Escalera al cielo). Yendo más atrás, me parece que el problema se deduce ya de Wittgenstein, con su clásica articulación entre juegos de lenguaje y formas de vida. Lo que Agamben llama hoy forma-de-vida 
(con guiones), en oposición a la vida desnuda, a la zoe, desciende directamente de aquellas formulaciones de Wittgenstein (aunque, naturalmente, pasa por Heidegger, rodeo que yo no soy capaz de dar por mí mismo. En ese bosque me pierdo). Me parece que esas nociones involucran necesariamente una consideración ética del discurso (y, por lo tanto, de la literatura). Ahora bien, una vez que accedemos a esa dimensión ética (bioestética o bioética, incluso lo anestético, la suspensión del arte como esfera separada) estamos ya en situación de posautonomía. Mi interés por lo imaginario tiene que ver con eso: las formas de vida wittgensteinianas no serían sino la contraparte (imaginaria, naturalmente) de los juegos de lenguaje. El programa del curso que vamos a dictar el año que viene en la Universidad de Buenos Aires se llama precisamente "Literatura y formas de vida" y se propone investigar ese lugar qualunque (para usar la categoría agambeniana) que es el soporte de una ética futura: que el mundo sea, que cualquier cosa pueda aparecer y tener rostro, que existan la exterioridad y el desocultamiento, como la determinación y el límite de cada cosa (esto es el bien).

Ahora bien: que exista la exterioridad (además del límite) y el desocultamiento (además de la determinación) nos obliga a un esfuerzo enorme de desmontaje de nociones adquiridas, entre las cuales están ciertas nociones “modernas” sobre lo imaginario (de Marx a Adorno, digamos). Yo, en ese debate, me adscribo más a la posición de Roland Barthes, sobre cuya obra vengo dictando un seminario hace dos años.

NF: ¿La noción de referencia (pensando a la vez en el “yo” y la “intimidad”) no se complica con ciertos autores como Aira o Matilde Sánchez? El valor presupuesto de lo "verdadero o falso" que creemos definitivamente desterrado, de una manera u otra vuelve en algunos planteos críticos (Sarlo, Giordano, etc.). Sin embargo, la escritura (manifestada en ciertos autores) o desestabiliza los créditos apriorísticos como estrategia de un cálculo lúdico (Aira) o funciona como síntoma de una "verdad” desplazada (Sánchez). ¿Se trataría, en lugar de liquidar por viejas ciertas categorías, de redituarlas en otros lugares del sistema de representación? ¿Perspectivas presupuesto, en cierta medida, en todo sistema de representación? ¿Qué hace Aira, más allá de intenciones improbables, sino apropiarse del nombre de Alberto Giordano (en Los misterios de Rosario) para construir un personaje (tan ficticio como real) y poner a prueba los efectos de ese uso en la construcción de otro sujeto, un destinatario condicionado, interpelado en su conocimiento? Giordano es un personaje, un monstruo, obeso, obsesivo, maníaco depresivo, un profesor al que no se le anotaron alumnos en su seminario y sufre una crisis. Aira corre los límites no tanto de lo que es y no es sino entre adentro y afuera del producto, del trabajo que es la escritura. Habrá lectores, a lo mejor extranjeros, que lean esa novela como si se tratara de un personaje más y posiblemente lo hagan de modo legítimo, "bien hecho” digamos. Pero hay otros que no se pueden sustraer (y vos Daniel hacés una diferencia muy sutil entre negación y sustracción) a “imaginar” un

Revista Iberoamericana, Vol. LXXVIII, Núm. 241, Octubre-Diciembre 2012, 1069-1075
ISSN 0034-9631 (Impreso) 
vínculo real. Sectorizado o no, universitario o no, de "amigos íntimos" o al menos que conozcan algunos caracteres verídicos y verosímiles. Como sea, Aira no es inocente. En El desperdicio, Matilde Sánchez tampoco, teniendo en cuenta además que el estatuto jurídico del nombre propio pareciera no verse afectado. Por supuesto que al que le de la gana puede leer al personaje femenino, a la protagonista de esa tragedia, como ficción absoluta. Sin embargo, me parece que lo que se juega ahí, como en Aira, no es tanto la invocación conceptual de la referencia (la novela nos habla de esto), sino la inscripción intelectual y emotiva (intimista y descarnada) del "yo" en relación con un destinatario, sin el cual, ese "yo" no existiría. ¿A quién se dirige Matilde? ¿Por qué el guiño? ¿Cómo soslayar, los que la conocimos y aquellos que la trataron profundamente, que esa mujer brillante es Mónica Tamborenea? Muchos de los "personajes" que la rodean tampoco pudieron evitar decir “esta soy yo" o "Mónica no fue esto”. Antes quise decir que Matilde evita nombrarla y con eso, me parece, da otro rodeo al riesgo empirista de apelar al acta civil de un sujeto real. Aira es todavía más arriesgado pareciera.

DL: Entiendo tu planteo (espero que quienes nos escuchen también) como una recusación al estatuto imaginario que le otorgo al "yo" en el libro. Ahora bien, no soy yo el responsable de esa colocación, sino lo que podríamos reconocer como "la ciencia de lo imaginario", se trate del marxismo o del psicoanálisis, que son precisamente quienes descalificaron la "realidad”, por decirlo de algún modo, del “yo” espontáneo.

En Fantasmas yo sostengo la hipótesis (un poco aventurada, por cierto) de que, en contra de lo que los lógicos han sostenido, el yo tiene una cierta estabilidad y no es totalmente deíctico, no es una categoría totalmente vacía. No siendo una descripción definida (que presupone existencia y que establece, por lo tanto, valores de verdad y de referencia); sin embargo, el "yo" (que es el hablante) presupone la existencia de aquel que sostiene el discurso. Me parece que eso transforma (tal vez complique irremediablemente) las cosas. Decís “Aira” o "Matilde Sánchez”, nombres propios que son totalmente singulares, pero que reconocemos como aquellos que sostienen tal o cual discurso. Yo podría declararme inocente en relación con esas figuras, "Aira”, "Matilde”, y decir que nada sé de ellas. Pero sé, al menos, que sostienen un discurso, y ese discurso me dice algo sobre esos nombres propios. Tal vez sea lo que Foucault llamaba la "función autor", no importa. Pero hay un resto (o ruina) de identidad en ellos y ese resto de identidad se deduce de sus textos. Ahora bien, el otro problema, vos decís que "Aira" escribe "Giordano" y "Matilde” no dice "Mónica” allí donde nosotros sabemos que se deja leer "Mónica". Curiosamente se trata, en los dos casos, de relaciones completamente imaginarias, relaciones de amistad (que es, no sólo una relación imaginaria sino además, narcisista, o sea, condenada).

Yo no creo que haya que olvidar al "Giordano" que designa el “Giordano” de "Aira” o ala "Mónica” que designa el personaje de "Matilde” (por lo tanto, no me pareceimportante decidir cuán fieles son en relación con la "verdad”: Giordano no es gordo y Mónica era

Revista Iberoamericana, Vol. LXXVIII, Núm. 241, Octubre-Diciembre 2012, 1069-1075 ISSN 0034-9631 (Impreso) 
brillante). Lo que importa es la relación en que aparecen esas figuras articuladas: en el caso de "Aira” y "Giordano" esa relación se llama Los misterios de Rosario. En el caso de "Matilde” y "Mónica” eso se llama El desperdicio. Para ser totalmente justos con esos textos yo no debo tratarlos ni como totalmente ficcionales ni como totalmente testimoniales. Es más: debo suspender la oposición entre ficción y testimonio y trabajarlos de otro modo, examinando una articulación compleja que pone a jugar el adentro (de un texto) con el afuera (mi propia memoria, mi propia experiencia, mi propio imaginario). Lo que vería allí, por lo tanto, no tiene que ver con problemas de representación sino con la colusión de imágenes o fantasmas. ¿Cómo se relaciona el nombre "Giordano" con la figura fofa? ¿ “Giordano” y “fofo” coinciden en algún punto de cualquier universo posible?

NF: ¿Cuando pensaste en Fantasmas, pensabas en la contracara material del monstruo? ¿Si hay diferencia, cuál sería? No son ambos, cicatriz de un "trauma”, "herida abierta”, resto, umbral. ¿'Son ambos inclasificables?

DL: No sé si pensaba en la contracara material del monstruo porque nada más monstruoso que las sirenas. No hay diferencias en ese sentido; y, sí, se trata de la misma cicatriz y el mismo umbral. Partí del planteo que hace del monstruo un inclasificable (un fugado de los sistemas de clasificación) y a los fantasmas, la persistencia de esas fugas o desclasificaciones. Una estrategia para resistir a la normalización, si se quiere. Las sirenas han sido objeto de todas las manipulaciones y todas las interpretaciones. Kafka, Adorno, Blanchot, Foucault han tratado de descifrar la (im)potencia de su canto. Constituyen, a todas luces (pero también en la línea de sombra), un problema central en la definición del esteticismo, la autonomía y, por supuesto, la imaginación inoperante en las estéticas del siglo xx. Las sirenas son no sólo monstruos: son el prototipo de funcionamiento de los fantasmas de la literatura, de la música y de la pintura. Vladimir Jankélevitch nos recuerda que, para Platón, "el Estado debe reglamentar, en el marco de una sana ortopedia, el uso de la influencia musical”, esto es: el canto de Orfeo (en oposición a la voz sirenaica). Enemigas de las musas, previas y hostiles al panteón Olímpico y derrotadas por el cantante apolíneo, las sirenas tienen el único objetivo de desviar y retardar el encuentro de Odiseo con su propia historia (que es, como se sabe, lo único que promete su canto, el canto mismo) y, así, "hacen descarrillar la dialéctica del recto itinerario que conduce nuestro espíritu”. El lírico, por su parte, "no doma a los monstruos cimerianos con el látigo: los persuade con la lira". Orfeo rinde a los leones, silencia a los gorriones, unge el toro al carro de trabajo y a la pantera a la carroza familiar: es esa marea civilizatoria a cuya margen las sirenas fueron desterradas (o decidieron colocarse, quién podría saberlo...). Ellas están en un más allá (desde, y al cual, convocan al viajero) de la humanidad que con su gracia construye Orfeo, a quien Platón, precisamente por eso, opuso al canto sirenaico, asimilándolo "a los ensalmos inconfesables y los recitativos embaucadores de la musa melíflua (demasiado suave y lisonjera para ser verídica y que, por ello, es

Revista Iberoamericana, Vol. LXXVIII, Núm. 241, Octubre-Diciembre 2012, 1069-1075
ISSN 0034-9631 (Impreso) 
más sirena que musa)". Lo que Platón propone es una vigilancia estatal que pueda sostener "el veto contra la 'musa cariana', la de los llantos y sollozos afeminados". Es lógico, como Kafka suponía, que las sirenas quedaran estupefactas al enterarse de un semejante rebajamiento de su potencia y que callaran. Por fortuna no callaron para siempre, y cada tanto dejan oír su voz para recordarnos que no debemos dejar de preguntarnos qué fue lo que hizo que en-callaran. Pienso, por ejemplo, en esas figuras que "lloraban con el buen tiempo y cantaban en la tempestad" según fueron presentadas por ciertos tratadistas italianos. En su Delle Imprese Trattato de 1592, Giulio Cesare Capaccio (1552-1634) reproduce una sirena en el primero de los libros que contiene. En contra del lugar común impuesto desde el siglo viI (la sirena de una, dos o tres colas ictícolas), la pictio de Capaccio muestra a una sirena pedes gallinaceous habente, con robustas piernas de gallina, delante de un monte en llamas y exprimiendo sus senos hinchados sobre una lira da braccio. Se trata (tal como lo denomina Emanuel Winternitz) de un bautismo lácteo idéntico al que, en un cuadro de autor anónimo flamenco del xvi, "Alegoría musical”, recibe un joven ejecutante de una viola de cinco cuerdas. La pictio va acompañada de la siguiente suscriptio: "vna Sirena in mezzo a Veseuo acceso fa stillar late dalle mamme", y el mote "Dum Vesubii siren incendia mulcet” (Mientras la sirena apaga el fuego del Vesubio). Podríamos aceptar que la sirena esté en medio del cráter del Vesubio, e incluso que de él ha salido (porque se trata, como sabemos, de una figura tectónica), pero en modo alguno resulta convincente la hipótesis bombera, y mucho menos comprensible que el comentarista de la imagen haya obviado la lira da braccio, sobre todo teniendo en cuenta que la época, equivocadamente, la consideraba un instrumento clásico (la lira de Orfeo o de Apolo, los armoniosos secuaces de las musas). Más bien pareciera que las sirenas, bien lejos de querer apagar el Vesubio, lo que pretenden es burlarse del instrumento órfico y, a través de él, de la manía civilizatoria de su dueño (sea éste Orfeo o su padre, el Musageta). Contra la cultura (contra el veto estatal a su potencia de seducción y a la sola promesa de su propio canto), la voz sirenaica viene a decirnos quién es el responsable de que en-calle.

NF: Volviendo un poco a lo anterior, ¿la imaginación (y su grado más o menos implícito de referencialidad), lo público y lo privado están directamente implicados con esto? En la sección que titulás "Método” y subtitulás “Cartas”, ponés algo que supera lo apócrifo y lo verídico, algo sin dejar de atravesar la zona íntima del “yo”. Quizá se trate de pensar(me) en vistas de "las prácticas sociales, las prácticas retóricas" que me elaboran y que elaboro, sobre la base del carácter, al decir de Antelo, acéfalo del discurso. Volviendo a lo anterior (y volviendo a tu intercambio epistolar con Antelo), ¿podría tratarse de una "repetición de la vida confiscada como biopolítica”, expuesta en su "extimidad”? (“Una pulsión de lo real, una experiencia de extimidad, algo más íntimo que la mayor intimidad, algo más expuesto, más extraño que la más extranjera de las actitudes”). Quiero decir, hay un plus en

\footnotetext{
Revista Iberoamericana, Vol. LXXVIII, Núm. 241, Octubre-Diciembre 2012, 1069-1075 ISSN 0034-9631 (Impreso)

ISSN 2154-4794 (Electrónico)
} 
tus “cartas”, algo real que excede, ahora a la inversa, a destinatarios “ciertos” o inventados (y esto más allá de pensar en cartas como registro verbal del pasado en la era ciber). Método, carta. De alguna manera se trata de una autobiografía; real y apócrifa, inventada (imaginada) y sucedida. Aparecen ideas, categorías, problemas, nociones, todo sujeto a revisión y puesto a prueba. El concepto de fantasma está allí, enunciado en su propio tejido, como señuelo para un lector sujeto a espera, dispuesto a saber sobre esos destinatarios, explícitos pero vaciados de su estatuto replicante (en el supuesto sistema de enunciación del registro). Me acuerdo por ejemplo de Una excursión, de Mansilla.

DL: Bueno, compararme con Mansilla tal vez sea un poco excesivo... Creo recordar que cuando volvió de París fue reprendido por su tío (Rosas) porque bajó del barco vestido con calzas. Yo nunca me he atrevido a tanto. En cuanto a la correspondencia.... Quise reinvindicar, precisamente, eso que muchos teóricos han planteado como pérdida: la idea de la comunidad de lectores como amigos que reciben cartas. En mi novela La ansiedad ya había ensayado el procedimiento, pero me pareció que acá iba a encontrar un lugar más hospitalario y me permitía, además, quebrar lo que de otro modo habría sido un discurso expositivo aburridísimo. No todos esos mensajes son previos al libro (necesité escribir algunos de ellos especialmente), pero la mayoría fueron, en efecto, intercambios epistolares con unos alumnos mexicanos para quienes dicté un seminario on-line. Naturalmente, tuve que reescribirlos enteramente para el libro. Ahora bien, esa preexistencia no les agrega "realidad", sino todo lo contrario, porque se trata de una escritura al cuadrado. Una vez aceptado eso, podría aceptar que esas cartas funcionen como un "efecto de real”, o sea, como una incrustación de algo exterior, extranjero, extraño, en definitiva, éx-timo.

NF: ¿Hay dos regímenes de fantasmagorías? ¿Habría una eficacia diferente para una imaginación sustentada en la pronunciación de la primera persona y otra (lo literario) donde el “yo” se sustrae a una despersonalización? Vos citás Crítica y clínica de Deleuze y trabajás mucho el concepto de neutralidad (Blanchot) y lo neutro (Barthes).

DL: Creo que no, precisamente porque lo que nos enseñan Deleuze, Barthes, Blanchot es que el "yo" es intercambiable con cualquier otra figura. Barthes habla muchas veces de sí en tercera persona. Basta leer Fragmentos de un discurso amoroso, o Roland Barthes por Roland Barthes, donde deliberadamente se abstiene de toda sistematicidad al respecto. Habitualmente estamos dispuestos a ser más tolerantes frente a alguien que dice: "me parece que este gobierno es un desastre” que ante alguien que dice "este gobierno es un desastre". Pero desde el punto de vista proposicional, los dos enunciados son equivalentes.

NF: Cuando marcás tu preferencia por imaginación e imaginario antes de imaginería (por la preeminencia de lo visual frente a los otros sentidos), ¿podemos pensar en JeanLuc Nancy y su Corpus? ¿Privilegiás texturas por encima de la idealización distante, metafísica y platónica de las imágenes ópticas?

Revista Iberoamericana, Vol. LXXVIII, Núm. 241, Octubre-Diciembre 2012, 1069-1075
ISSN 0034-9631 (Impreso) 
DL: Yo de Platón no sé nada, salvo el platonismo que se me puede haber pegado a través de otras lecturas. Pero en general le tengo antipatía. Habiendo abrazado la causa deleuziana en mi adolescencia, puedo creerme a salvo de sus rigores. Por lo mismo, traté de obviar (en la medida de lo posible) el aparato óptico como matriz de conceptualización. Por eso empecé con las sirenas (con su canto) y propuse una teoría de la memoria calcada de la teoría física a propósito del sonido (cosa que ya había hecho Sarduy, a su manera). Hay mucha teoría de dementes en Fantasmas. Aby Warburg, sin ir demasiado lejos, y los dementes suelen tener más alucinaciones auditivas que visuales (el caso de Daniel Schreber, mi tocayo, es el más conocido). En todo caso, lo que intenté demostrar (se trate de la infancia, la memoria, la irresistible manía apocalíptica) es que las imágenes hablan: sostienen, también ellas, un discurso que pretende seducirnos. Yo creo que hay que escucharlas, creo que hay que dejarse llevar por esa monodia y esa persistencia. Como decía Barthes: todo es señuelo, pero hay, para nosotros, un tiempo de señuelo.

Fernández, Nancy. “Diálogo con Daniel Link”. Literatura, política y cambio. 2 noviembre 2009. <www.vanguardiaytradicion.blogspot.com/2009/11/dialogo. html> 17 septiembre 2012.

Revista Iberoamericana, Vol. LXXVIII, Núm. 241, Octubre-Diciembre 2012, 1069-1075
ISSN 0034-9631 (Impreso) 
